\title{
A Computational Model of the Human Hand 93-ERI-053
}

K. Hollerbach, P.I.

T. Axelrod, original P.I.

Precelle

APR 12 1950

OSTI

March 1996

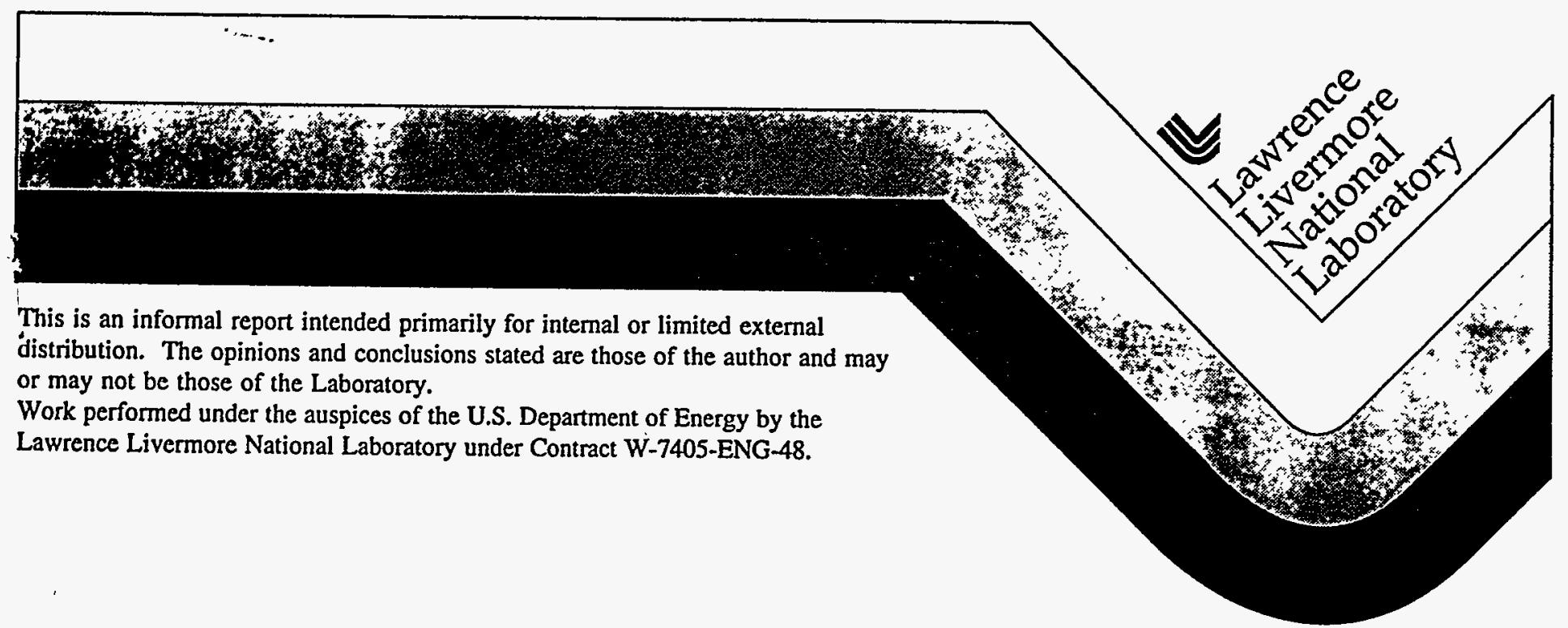


This document was prepared as an account of work sponsored by an agency of the United States Government. Neither the United States Government nor the University of California nor any of their employees, makes any warranty, express or implied, or assumes any legal liability or responsibility for the accuracy, completeness, or usefulness of any information, apparatus, product, or process disclosed, or represents that its use would not infringe privately owned rights. Reference herein to any specific commercial products, process, or service by trade name, trademark, manufacturer, or otherwise, does not necessarily constitute or imply its endorsement, recommendation, or favoring by the United States Government or the University of Callfornia. The views and . gpinions of authors expressed herein do not necessarily state or reflect those of the United States Government or the University of California, and shall not be used for advertising or product endorsement purposes.

\author{
Printed in the United States of America \\ Available from \\ National Technical Information Service \\ U.S. Department of Commerce \\ 5285 Port Royal Road \\ Springfield, VA 22161
}

Price

Code

A01

Microfiche

Papercopy Prices

$\begin{array}{ll}\text { A02 } & 001-050 \\ \text { A03 } & 051-100 \\ \text { A04 } & 101-200 \\ \text { A05 } & 201-300 \\ \text { A06 } & 301-400 \\ \text { A07 } & 401-500 \\ \text { A08 } & 501-600 \\ \text { A09 } & 601\end{array}$




\title{
A Computational Model of the Human Hand 93-ERI-053
}

\author{
K. Hollerbach, P.I. \\ (T. Axelrod, original P.I.)
}

Final Report

\section{Introduction}

The objectives of the Computational Hand Modeling project were to prove the feasibility of applying the Laboratory's NIKE3D finite element code to orthopaedic problems. Because of the great complexity of anatomical structures and the nonlinearity of their behavior, we have focused on a subset of joints of the hand and lower extremity and have developed algorithms to model their behavior. The algorithms developed here solve fundamental problems in computational biomechanics and can be expanded to describe any other joints of the human body. This kind of computational modeling has never successfully been attempted before, due in part to a lack of biomaterials data and a lack of computational resources. With the computational resources availabie at the National Laboratories and the collaborative relationships we have established with experimental and other modeling laboratories, we have been in a position to pursue our innovative approach to biomechanical and orthopedic modeling.

Motivation for the research lay in the following areas:

(1) The high cost of repetitive motion injuries to the upper extremity (over $\$ 30$ billion per year in medical costs in the U.S.) makes developing tools for evaluating hand function a health care priority.

(2) Assessment of outcome of surgery following traumatic or repetitive motion injury to the hand is made possible by the development of the complete hand model.

(3) The tools developed in this project are used in analysis of orthopaedic images of other body parts.

(4) Progress made in developing sophisticated segmentation and finite element tools is directly applicable to other areas of computational medicine.

(5) The models dramatically improve LLNL's ability to model complex material systems.

\section{Starting Point in 1993}

The Computational Hand LDRD project began in 1993, with a very small group of researchers in the Institute for Scientific Computing Research (ISCR) contemplating the need for a highly detailed, anatomically realistic hand biomechanics model that could be developed rapidly, on a patient-specific basis. At the time, the ISCR research group was working alone in this area, with none of the required modeling tools in existence. After several years of research experience in this area, the present Computational Biomechanics Group is aware of the interdisciplinary challenges and monumental tasks that faced the initial research group. Although not all of the original milestones presented in 1993 were accomplished due to unforeseen technical challenges, the accomplishments of the research performed under the auspices of the Computational Hand LDRD project are significant. In order to highlight these research accomplishments, it is worthwhile to remind the reader of the modeling tools that are required in this modeling process but that did not exist when the project began: Development of the human joint models has always depended upon the existence of high quality, high contrast, high resolution, 3D scanned data sets. No such data 
sets existed at the outset of the modeling project: MRI technology did not yet provide access to high enough resolution (in all three dimensions), and few experiments had been performed to provide data on maximizing contrast among the various soft tissues imaged by magnetic resonance. Similarly, the ISCR had no immediate access to pre-processing tools such as segmentation and surface extraction software. Bio-material models for most orthopaedic tissues that were suitable for finite element modeling were virtually absent in the literature and needed to be generated and implemented within the finite element code. The ISCR had no finite element code of its own; existing codes needed to be evaluated and the possibility of having to write an entirely new nonlinear, 3D finite element code, specifically tailored to biomechanics.problems, needed to be addressed. Finally, physiologically accurate boundary conditions for the finite element analysis needed to be generated. None of these required modeling tools and input data was available when the Computational Hand Modeling Project begin in 1993. Each was developed either by the ISCR or by one of the collaborating groups that were identified in the course of this LDRD project.

\section{Research Results}

Model development included several steps including data acquisition, segmentation and surface extraction, volumetric mesh generation, boundary condition evaluation, material modeling, and finite element analysis (Figure 1). Research progress in each of these areas will be discussed separately, below.

\section{Data acquisition}

We acquired high resolution, three dimensional (3D) computed tomography (CT) scans and magnetic resonance images (MRD) of human joints, including all joints in the hand, the knee, and some additional joints in the upper and lower extremities. Since the ISCR does not directly have access to CT or MRI facilities, we have collaborated with several groups that have provided us with research-quality scanned data sets. These groups have included:

\begin{tabular}{|lll|}
\hline Source & Data Type & Joint(s) \\
Hull Royal Infirmary, England & high resolution MRI & hand \\
University of California, San Francisco & high resolution MRI & knee, hand \\
Massachusetts General Hospital & high resolution MRI & knee \\
Non-Destructive Evaluation, LLNL & high resolution CT & hand \\
\hline
\end{tabular}

To obtain the high resolution CT data for soft/hard tissue geometries, the on-site facilities and expertise of the Non-Destructive Evaluation (NDE) division at LLNL were used. (Research in this area is continuing in FY96, in an on-going collaborative effort between the ISCR and NDE. However, CT scans of human joints by NDE were started under the FY 95 LDRD Modeling Project.) Typically, scanners used in the medical field have a spatial resolution of up to $1 \mathrm{~mm}$, which is not acceptable for a precise definition of articular surfaces. Thus, an amputated hand was scanned with one of the industrial scanners that have been designed and constructed at the LLNL. The PCAT scanner was used, which can be reconfigured to handle objects of various sizes and attenuations. The pixel size of the PCAT scanner is 150 microns, and is equal to the distance between CT slice planes. Thus, PCAT makes it possible to acquire high-spatial resolution isotropic volume elements (voxels). PCAT uses a $450 \mathrm{kVp} \mathrm{X-ray} \mathrm{source} \mathrm{and} \mathrm{a} \mathrm{scintillating} \mathrm{screen} \mathrm{lens}$ 
coupled to a 14-bit camera. This $2 \mathrm{D}$ detector helps acquire 720 projections ( 2.5 Gigabytes) rapidly. The reconstruction step is the most computationally-intensive and is performed using a parallelized Convolution Back-Projection (CBP) algorithm on a Silicon Graphics Onyx graphics hardware. This fan-beam approximation to a cone-beam geometry only holds since the field of view was limited to a half-cone angle of 2 degrees. Future experiments will use a cone-beam reconstruction algorithm and a larger magnification ratio. Several experiments were performed in order to assess the effects of data preprocessing and volume reconstruction. Removing the bad pixels that appear when a photon hits the CCD directly made the segmentation significantly easier. The correction for beam-hardening also proved extremely useful from the segmentation point of view. Several experiments were performed in order to choose the "best" cut-off frequency.

The MRI data came from several sources off-site. These included well-known research hospitals that continue to engage in research activities with the ISCR/Computational Biomechanics Group. The MRI data sets that we have obtained for this project have a spatial resolution in the submillimeter range, down to 100 microns (isotropic, i.e., in all three dimensions) (Figure 2). Due to difficulties in identifying clearly the boundaries of all soft tissues (e.g., muscles, tendons, fat, skin) surrounding each joint, several contrast-enhancing methods were tested, such as varying T1/T2 weighting, injection of contrasting agents (gadolinium), and fat suppression. The conclusion from the entire database of CT and MRI was that both CT and MRI of the same joint were required for accurate definition of the bones, including their articular surfaces (CT), and of the deforming soft tissues (MRI).

\section{Surface extraction}

The process of surface extraction from 3D data sets can occur along two parallel paths that both result in the creation of a polygonal (triangulated) surface in 3D. The first method that we used was based on the VoxellMan software created by our collaborators in the Institute for Mathematics and Computer Science in Medicine in Hamburg, Germany. This approach was voxel (volumetric element) based, in that each voxel was labeled as belonging to some particular tissue type (e.g., skin or flexor muscle). This process was fully 3D but extremely labor intensive and time consuming. Once completed, however, the tissue types were rendered in 3D and the resulting objects could be turned into polygonal surface definitions using the Marching Cubes algorithm. The Marching Cubes results, for surfaces of the size, resolution, and complexity found in our data, typically had millions of triangles. As a result, the surfaces were passed through a decimation software package that reduced the number of triangles, while preserving significant surface features.

A parallel method of segmentation and surface extraction makes use of a $2 \mathrm{D}$ based segmentation tool (Visu) that was developed at LLNL in FY 95 for processing CT data. The reconstruction of surfaces from volume data is an on-going research area for ISCR, ME, and NDE: We now have tools for iso-surface extraction techniques and edge detection using semi-automatic segmentation and classification, as well as decimation algorithms to reduce the number of polygons composing the surfaces without loss of accuracy. (These tools will be integrated into an interactive software environment to facilitate use by others at the Laboratory.) Segmentation of the human joints was made difficult by the inhomogeneous trabecular structure of the bones. Choosing a threshold in a robust way was almost impossible, since the initial density histogram was unimodal. Similarly, edge detectors produced a large number of spurious edges. Our approach relied on a simple model of the bone attenuation profiles. A 3D gray-scale morphological reconstruction removed the texture and filled in the bones. The histogram became bimodal, and markers could then be extracted. This coarse segmentation was improved by computing the watershed lines, which are by construction located on gradient peaks and hence on sharp boundaries. These morphological operators relied on ordered queues, which helped decrease segmentation time dramatically. Our attenuation model and 
the morphological approach were satisfactory in most cases. However, human interaction will always be needed to correct the coarse segmentation or the end-result. This kind of interaction requires computational tools that allow the user to visualize large data sets, manipulate the colormap to display false colors, perform interactive thresholding, overlay the segmentation mask, and save the corrected results. The results of this software package were a series of contours, defining the boundaries of tissues of interest in each CT slice (Figure 3). The contours were linked to form the final polygonal surface in 3D (Figure 4).

\section{Volumetric mesh generation}

The process of mesh generation is one very important step in the development of $3 \mathrm{D}$ computer graphics and in the development of 3D finite element models of biological structures. In mesh generation, a data set describing a surface in 3D is "gridded" i.e., a set of small polygonal, volumetric elements is generated that closely approximates the volume bound by the original 3D surface. In our modeling process, mesh generation consumed a large portion of the entire model development time, since hexahedral meshes were used throughout the entire structure. A "library" of mesh generation templates for all human finger and thumb bones was developed. The meshing templates can be used to rapidly mesh any "normal" human hand bones segmented from any scanning method, such as CT or MRI. This meshing technique is being extended to cover additional structures of interest to the ISCR, but can now be applied to any new hand scans, for patient specific hand modeling. A more detailed description of the template meshing process follows:

Due to normal and sometimes pathological variations in anatomy, each person's finger bones are of a slightly different shape and size. However, since similarities usually outweigh differences, the problem of generating a mesh for each bone in all fingers of different people is greatly diminished by the development of one or more templates, each of which can be used to mesh more than one bone. In the method used to automate mesh generation, one template out of a library of templates is chosen; based on the geometry of the surface to be gridded, and then deformed to fit that geometry. A particular pre-defined (for the chosen template) sequence of steps to compute the volumetric grid is then performed.

We have made a library of structures that are included in the hand finite element model. We have demonstrated the validity of the library by using it on all finger bones (within a particular hand data set), thereby producing a high-quality mesh for each bone. Our work relied on the TrueGrid (XYZ Scientific Applications, Inc.) meshing package. The gridding algorithm that was used begins with determining a series of centroids, where each centroid is calculated in a plane that is perpendicular to the long axis of the bone. The centroids are then connected in a line that forms the "spine" of the long bone. A number of planes are cut through the bone, each plane perpendicular to the spine at the centroid. The cross section of the bone is evaluated in each plane, and an index of variation from plane to plane is determined. Higher indices of variation result in finer local meshing. The spine is then copied multiple times, and each copy is translated radially. Finally, a set of radial planar surfaces is added; all radial surfaces meet at the spine. The outer edge of each surface is defined by the original surface grid. To form the actual volumetric mesh, the computational (originally block shaped) mesh is placed inside the bone, and its vertices and faces are projected in a multi-step process in such a way that each vertex lies at the intersection of the perpendicular cut plane and the outer edge of the closest radial surface, and each face approximates the original surface grid. With all vertices and faces in place, the internal nodes are then arranged to optimize the grid quality. The final results obtained were high quality bone meshes that are suitable for finite element modeling. Diagnostic measures, such as orthogonality of the elements, may be applied to confirm the mesh quality. Other tissues obtained from an MRI input data set were meshed manually (without templates) with similar results. 


\section{Finite element modeling results}

We have developed finite element models of several human joints, including several digits of the hand as well as the knee. Some representative pictures of finite element modeling results follow (Figures 5 \& 6).

\section{Material modeling: NIKE3D code development}

Finite element codes frequently do not include the capability to combine finite element modeling with rigid body modeling. In the biological systems that have been modeled, this capability is routinely needed. As a result, the NIKE3D finite element code was taken and extended to allow for mixed finite element/rigid body modeling approaches. For example, the relative elasticity of various materials found in human joints varies widely. In our knee model, we have modeled the bones as rigid materials, and the surrounding soft tissues as hyper-elastic. This rigid body addition to the code allowed us to spend computational resources selectively where they were most appropriate for the particular system being modeled.

A second extension to the NIKE3D finite element code has been the development and implementation of a nonlinear, transversely isotropic, hyper-elastic material model that was used to simulate ligament behavior in the joint simulations. As is the case with most commercial codes, the NIKE3D code was originally developed in LLNL for engineering purposes and did not include models specific to biomaterials. With current applications of the code to biomechanics, however, biomaterial models became significant extensions to the existing code. Additional biomaterial models that are currently being developed include bone models that will be used in analyses of bone remodeling (e.g., in growth and in osteoporosis) and of prosthetic implant/human bone interface conditions during physiological loading of the implants.

\section{Collaborations}

In completing the research for the Computational Hand LDRD project, a number of significant and successful research collaborations were formed. Several have been particularly instrumental in ensuring the success of the modeling project:

\section{LLNL collaborators}

- Applied Mechanics, ME

- Center for Health Care Technology

- Health Services:

- Methods Development, ME

- Non-Destructive Evaluation, ME

Outside collaborators

- ArthroMotion

- GW Long Hansen's Disease Center

- Inst. for Math. \& CS in Medicine

- LSU Medical Center

- Massachusetts General Hospital

- Orthopedic Biomechanics Institute

- Salishan KDC Group finite element modeling

orthopaedic industry partnerships

experimental model validation; joint kinematics

NIKE3D code development, material models

high resolution CT scans

data sets, boundary conditions

kinematics, boundary conditions

segmentation tools

clinical advisor, kinematics

high resolution MRI

finite element modeling, experimental testing

kinematics, boundary conditions 
- Sandia National Laboratory

- UC Berkeley

- UC San Francisco

- XYZ Scientific Applic. Inc. high resolution MRI (from Hull Royal Infirmary)

finite element modeling (bone)

high resolution MRI

mesh generation tools

\section{Conclusion}

The modeling approach taken in this LDRD project is a radical departure from previous joint biomechanics modeling efforts. Previous investigators have traditionally studied biomechanics from a rigid body, kinematics/dynamics perspective, in which soft tissue deformation has not been considered. Finite element analyses of biological tissues have typically included small volumes of single tissue types. Primary reasons for this have included lack of computational power, lack of finite element codes that had the capabilities to solve difficult, nonlinear, 3D problems such as those found in biological articulation with contact of deformable materials, lack of appropriate material models, and more. As a result, traditional models have included user imposed definitions of kinematic behavior, through selection of kinematic axes of rotation for each joint, and simulations of motion have been confined to the motions allowed by these axes. Our modeling approach has, for the first time, allowed our models to simulate joint motion in a physiologically more realistic manner: as in nature, the joint articular surface geometry itself defines the motion; motion is not defined by some preconceived notion of the investigator. We have thus achieved a quantum leap in the understanding of joint motion and in the development of tools to further such understanding.

The LDRD project itself has come to a successful conclusion. However, due to the challenging interdisciplinary nature of the project, several promising spin-off projects are currently underway: In FY 96, we are applying the human joint modeling tools to prosthetic joint implants, in an effort to improve the implant design and manufacturing process, thereby making implants cheaper to produce, perform better when implanted into the patients' joints, and less likely to fail due to kinematic and material wear problems. In addition, we currently have a small business CRADA with an orthopaedic company for whom we are analyzing a knee implant design. In this agreement, we are using the LDRD developed finite element models of the knee as well as newly developed implant models. We expect additional interest in this and related work from the orthopaedic industry as well as other agencies and businesses with an interest in ergonomic issues and sports biomechanics injuries.

\section{Selected-LDRD Related Papers \& Presentations}

Ashby AE, et al. (1995) "LLNL High Resolution Extremity CT for Biomechanics Modeling", Proceedings, IEEE/EMB 17th Annual International Conference, Montreal.

Bossart P-L, Martz HE, Brand HR, Hollerbach K, and Underhill KC (1996) "Finite element analysis of human joints based on high-resolution X-ray CT and on template-based volumetric meshing", submitted to the Computer Vision and Pattern Recognition Proceedings to be held in San Francisco in June 1996.

Bossart P-L , Martz HE, Brand HR, and Hollerbach K (1995) "Application of 3D X-ray CT data sets to finite element analysis", submitted to Review of Progress in Quantitative Nondestructive Evaluation, D. O. Thompson and D. E. Chimenti, Eds. (Plenum Press, New York, to be published) and UCRL-JC-120894, Lawrence Livermore National Laboratory, Livermore, Calif.

Brand HR, Schneberk DJ, Martz HE, Bossart P-L, and Azevedo SG (1996) "Progress in 3-D Quantitative DR/CT", Lawrence Livermore National Laboratory, Livermore, Calif., UCRL53868-95; Lawrence Livermore National Laboratory, Livermore, Calif., UCRL-ID 115668. 
Hollerbach K, Schauer D, Ashby E (1995) "Modeling the biomechanics of human joints and prosthetic implants", UCRL-TB-118601-Rev.1, University of California, Lawrence Livermore National Laboratory.

Hollerbach K, Hollister A (1995) "A mathematical analysis of the errors inherent in the use of Euler angles to describe joint motion", J. Biomech. Engr. (submitted).

Hollerbach K, Underhill, KC, Rainsberger R (1995) "Automated volumetric grid generation for finite element modeling of human hand joints", 1995 ASME Summer Bioengr. Conf.

Hollerbach K, Hollister A (1995) "Displacements and rotations of a body moving about an arbitrary axis in a global reference frame", 1995 Winter Mtg. of the ASME.

Hollerbach K, Hollister A (1995) "Mathematical analysis of errors resulting from the choice of reference frame coordinates in measuring human joint motion", Second Triennial Intl. Hand and Wrist Biomechanics Symp.

Hollerbach K, Hollister A (1995) "Mathematical analysis of errors inherent in the use of Euler angles in measuring joint motion", XVth Congress of the Intl. Soc. of Biomechanics.

Hollerbach K, Hollister A, Chen C, Burastero S, Shih M, (1994) "Offset hinges in the wrist joint: model predictions and verification", Annual Mtg. of the Amer. Soc. Biomech.

Hollerbach K, Schauer D, Ashby E (1994) "Patient-specific modeling of joint function", Lawrence Livermore National Laboratory Exhibit, 1994 SuperComputing Conference, San Diego.

Moor EH, Schauer DA, and Weiss JA (1995) "Mesh Generation for a finite element model of the human leg," The 1995 ASME Summer Bioengineering Conference, Beaver Creek, Colorado.

Nielsen C, Hollerbach K, Perfect S, Underhill K (1995) "A computational method for comparing the behavior and possible failure of prosthetic implants", 1995 IEEE Intl. Conf. of the Engineering in Medicine and Biology Society.

Puso MA, Weiss JA, Maker BN, and Schauer DA (1995) "A transversely isotropic hyper elastic shell finite element," The 1995 ASME Summer Bioengineering Conference, Beaver Creek, Colorado.

Puso MA, Weiss JA (1995) "Finite element implementation of anisotropic quasilinear viscoelasticity using a discrete spectrum approximation", In review, ASME J Biomech Engr.

Puso MA, Weiss JA, Maker BN, Schauer DA (1995), "A hyperelastic shell element for modeling transversely isotropic soft tissues", Proceedings, U.S. National Congress for Computational Mechanics, 3:218.

Weiss JA, Maker BN, and Schauer DA (1995) "Treatment of initial stress in hyper elastic finite element models of soft tissues," The 1995 ASME Summer Bioengineering Conference, Beaver Creek, Colorado.

Weiss JA (1995) "A model for the material behavior of ligaments and tendons," The 1995 ASME International Mechanical Engineering Congress and Exposition, San Francisco, California.

Weiss JA, Gardiner JC, and Quapp KM (1995) "Material models for the study of soft tissue mechanics." Proc Conference on Pelvic and Lower Extremity Injuries, Wash. D.C.

Weiss JA;-Maker BN, Govindjee S (1995) "Finite element implementation of incompressible, transversely isotropic hyperelasticity", U.C. Berkeley Report \#UCB/SEMM-95-07 June 1995 (In press, Computer Methods in Applied Mechanics and Engineering, December 1995).

Weiss JA, Beck CL, Levine RE, Greenwald RM (1995) "Effects of platelet-derived growth factor on early medial collateral ligament healing", Trans 41st Annual Orthopaedic Research Society 20(1):159.

Weiss JA, Maker BN, Schauer DA (1995) "Inclusion of residual stress in finite element models of transversely isotropic soft tissues", Proceedings, U.S. National Congress for Computational Mechanics, 3:221. 


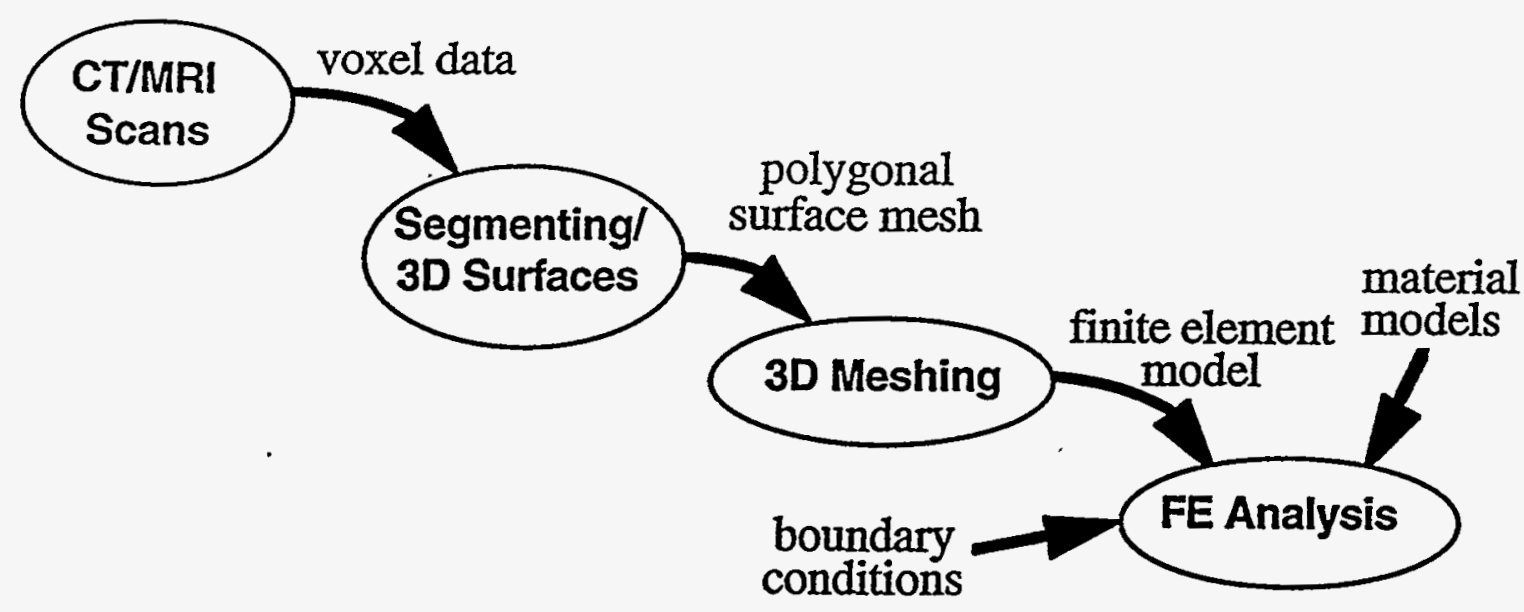

Figure 1: Simplified flow chart of model development process.

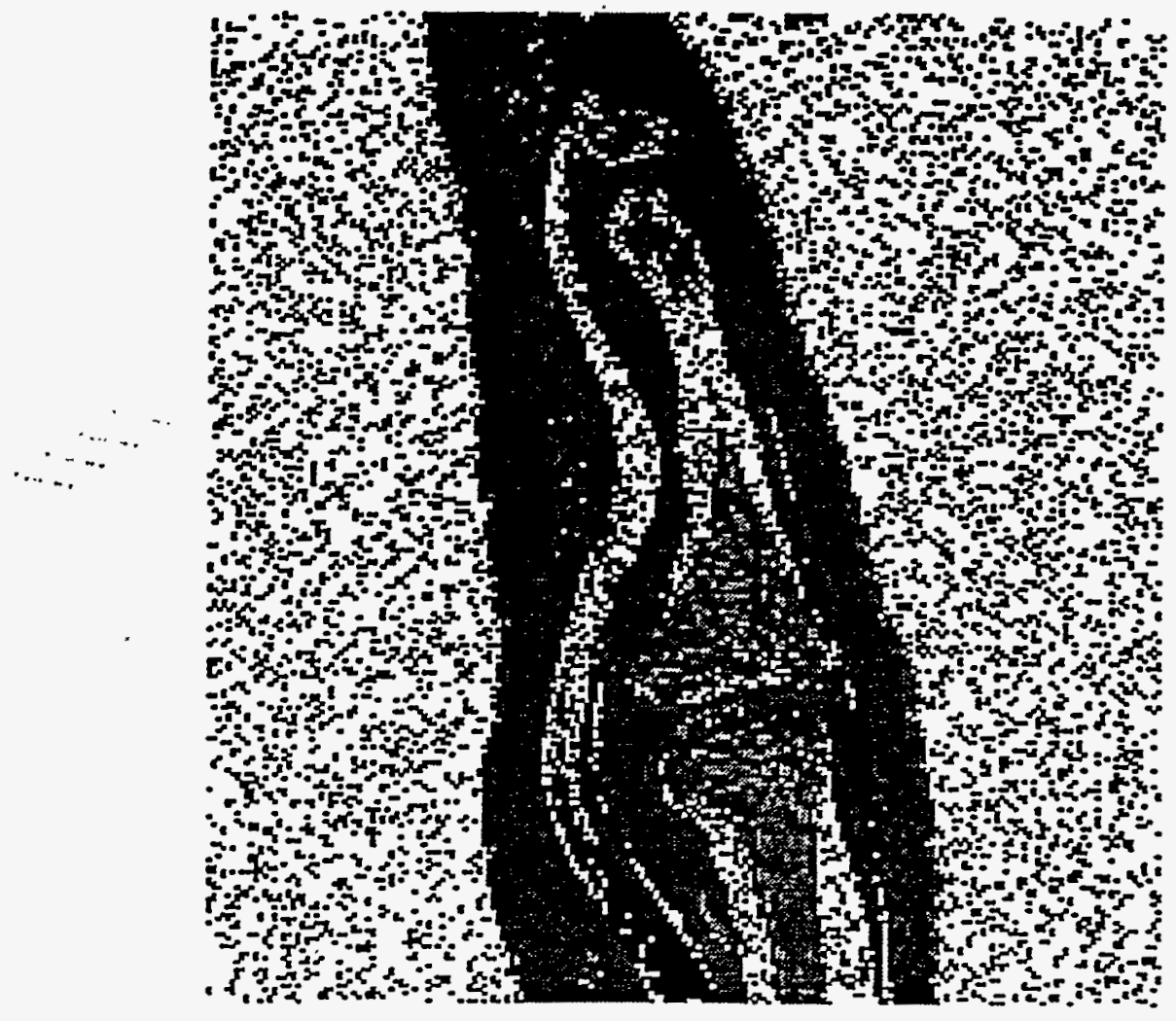

Figure 2: High resolution MRI of the fingertip (source: Hull Royal Infirmary, England). 


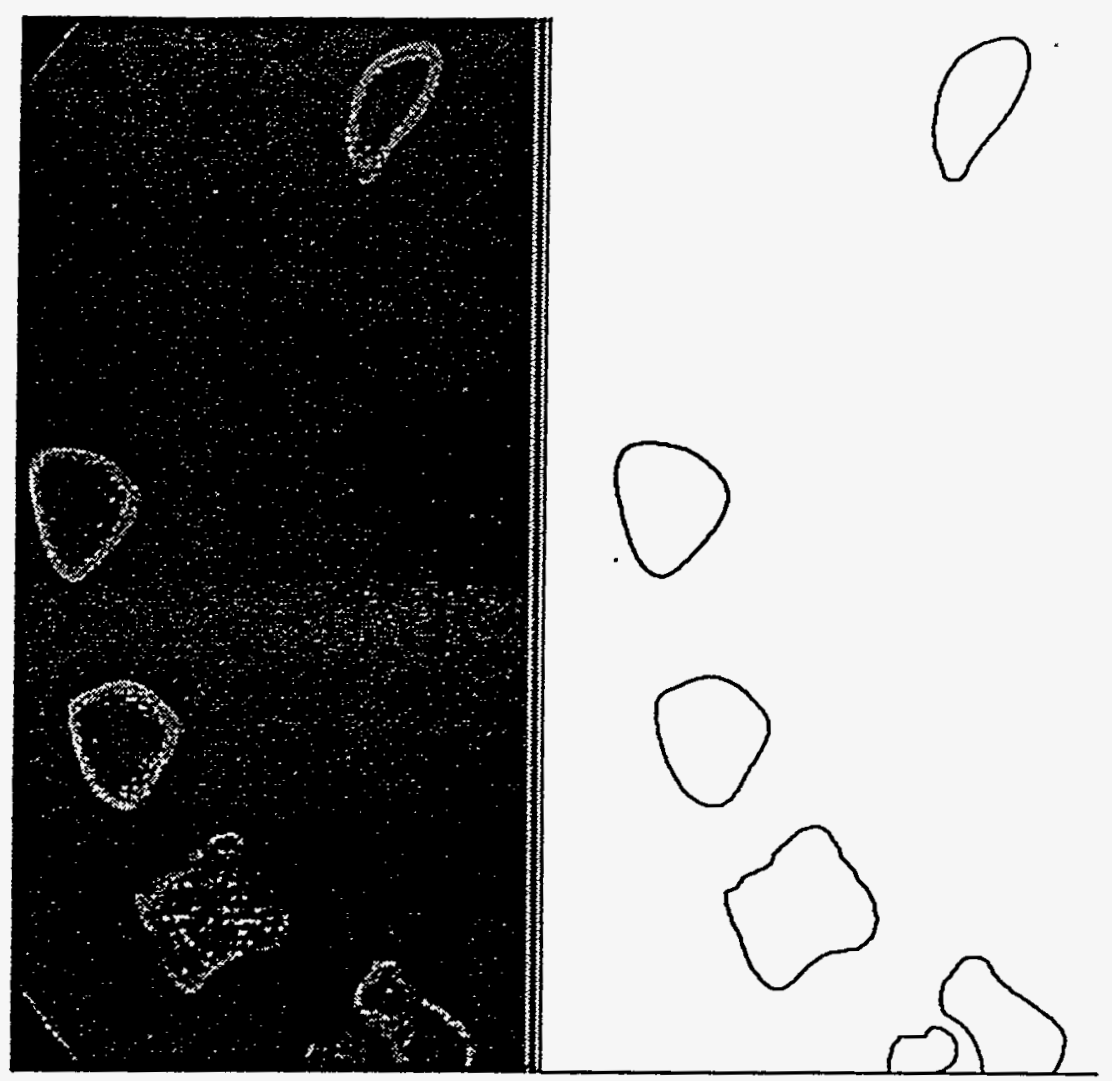

Figure 3: 2D based segmentation of high resolution CT scan of hand. $\cdots, \cdots$
$\cdots \cdots$ 


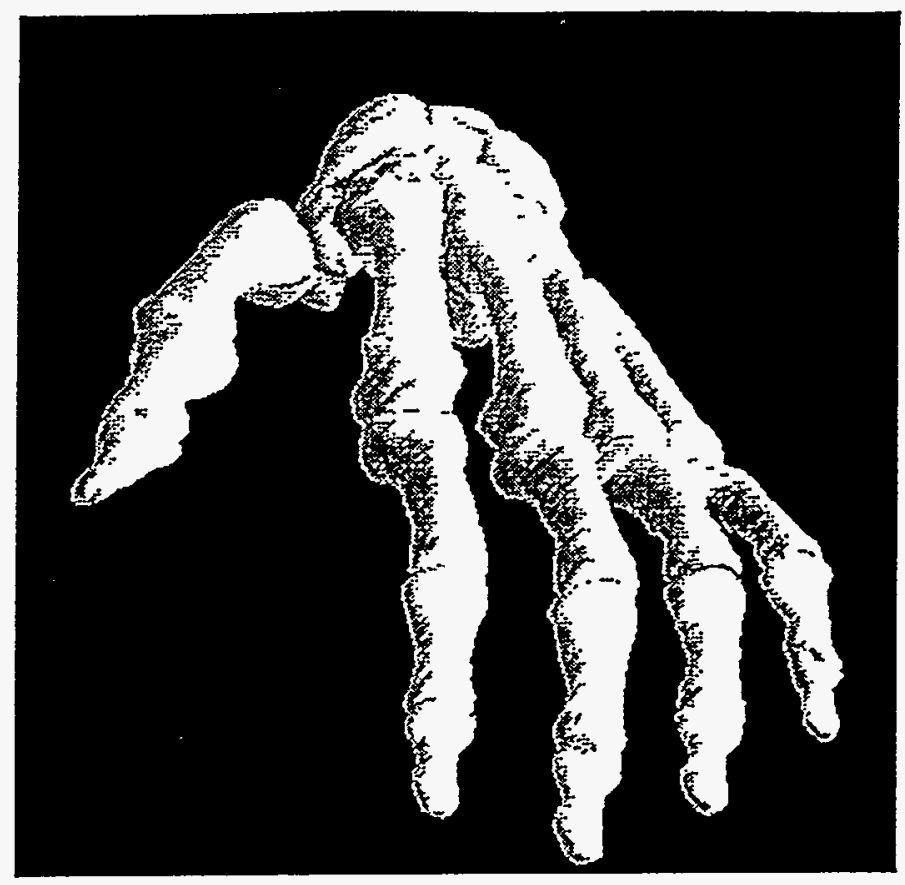

Figure 4: Bone surfaces extracted from high resolution CT scan of hand.

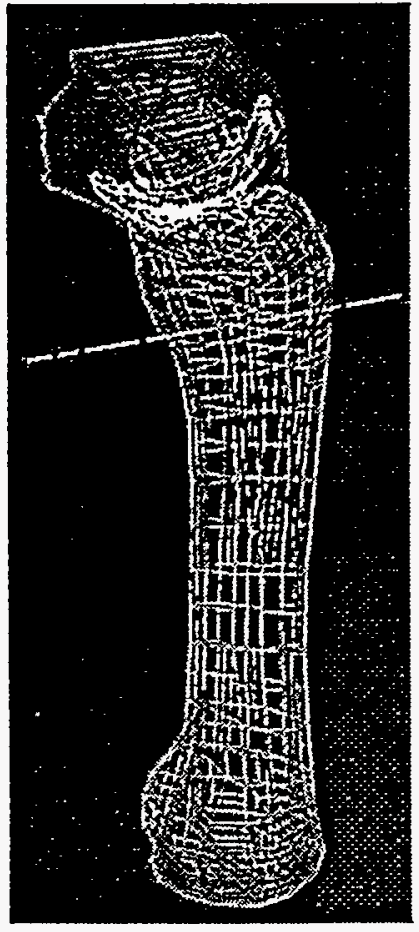

Figure 5: Finite element model of thumb carpo-metacarpal joint.

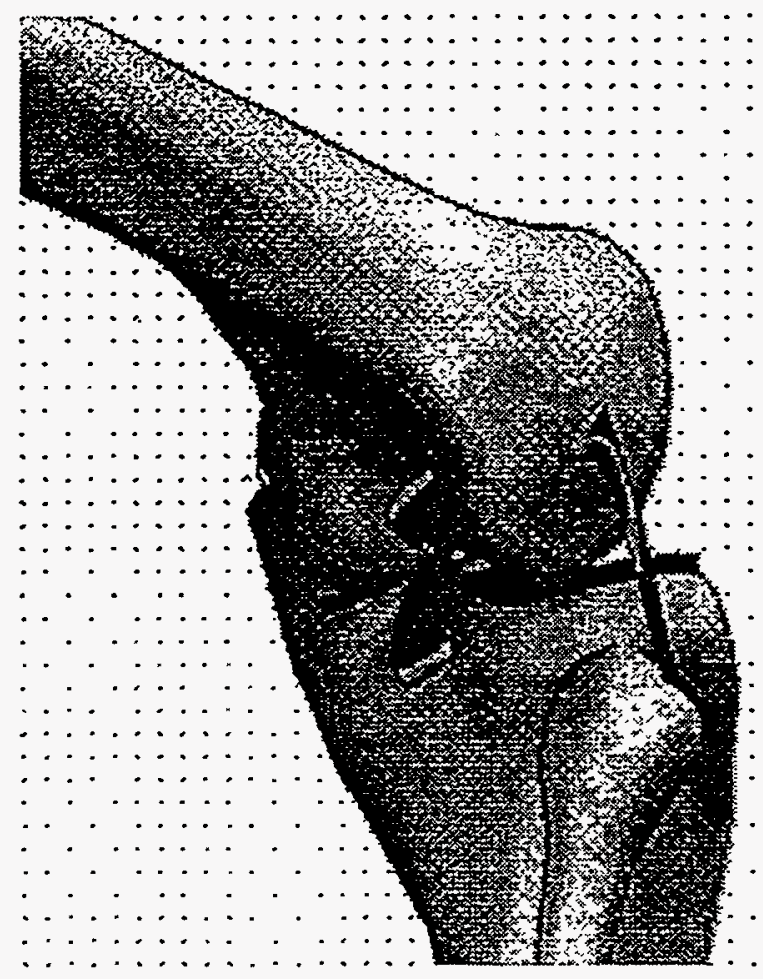

Figure 6: Finite element model of knee, showing flexion/extension movement. 
<013> DATE-COMPIETED

$<014>$ DATE-OF-RECORD-ENTRY

$<015>$ DATE-RECEIVED

$\langle 016\rangle$ CORIES-RECEIVED

$<020>$ DOCUMENT-TYPE

$<022>$ MEDIUM-CODE

$<030>$ CIASSIFICATION-CODE

<050> GPO-SUPERINTENDENT-OE-DOCUMENTS

$<072>$ PERSONAI-AUTHOR-AND-AFEILIATION

$<080>$ SPONSORING-ORGANIZATION-CODE

<110> TITLE-ENGLISH

<150> PRIMARY-REPORT-NUMBER

$<240>$ CONTRACT-NUMBER-DOE

<241> ABBREV-CONTRACT-NUMBER-DOE

$<242>$ AWARDING-OFFICE-CODE

$<243>$ BUDGET-REPORTING-CODE

<245> IEGIBILITY-CODE

$<246>$ DOE-INITIATING-OFFICE-CODE

<247> MICROFICHE-DISTRIBUTION-CODE

<248> VENDOR-ID-CODE

$<249>$ VENDOR-NAME

$<251>$ REPORTING-REQUIREMENT

$<276>$ DUPCHECK-BYPASS-ETAG

<291> PACKED-PRIMARY-REPORT-NUMBER

$<293>$ PREFIX

<295> INDEX-DOCUMENT-NUMBER

$<370>$ PUBLICATION-DATE

<376> REPORT-TYPE-CODE-AND-FREQUENCY

$<390>$ PAGES-BIBLIOGRAPHIC

$<400>$ REPORT-DISTRIBUTION-CODE

<421> IANGUAGE-CODE

$<425>$ AUDIENCE-CODE

<426> ITMITATION-CODE

$<510>$ DISTRIBUTION-CATEGORY

$<520>$ PROJECT-STATUS

$<530\rangle$ ANNOUNCEMENT-CODE

$<540>$ EDB-SUBUECT-CATEGORTES

$<550\rangle$ SOURCE-OF-BIBLIOGRAPHIC-INPUT

<560> COUNIRY-OF-INTELIECTUAL-ORIGIN

$<570>$ COUNITRY-OF-PUBLICATION

<686> DOCUMENT-STATUS-CODE

$<700>$ CORPORATE-CODE

<801> SUBJECT-DESCRIPTORS

HANDS:TI;MANIPULATORS;COMPUTERIZED STMULATION;FINITE DIFEERENCE METHOD;N CODES;

<931> AVAIIABILITY-CODE MATHEMATICAI MODELS:Q1;ALGORITHMS; ROBOTS; HUMAN FACTORS ENGINEERING:T

$<950\rangle$ ABSTRACT

The objectives of the Computational Hand Modeling project were to prove the feasibility of the Laboratory's NIKE3D IInite element code to orthopaedic problems. Because of the great complexity of anatomical structures and the nonlinearity of their behavior, we have focused on a subset of joints of the hand and lower extremity and have developed algorithms to model their behavior. The algorithms developed here solve fundamental problems in computational bicmechanics and can be expanded to describe any other joints of the human body. This kind of computational modeling has never successfully been attempted before, due in part to a lack of bianaterials data and a lack of computational resources. With the computational resources available at the National Iaboratories and the collaborative relationships we have established with experimental and other modeling laboratories, we have been in a position to pursue our innovative approach to

biomechanical and orthopedic modeling.
960517

960415

2

$\mathrm{H}$

Uncl

Hollerbach, K.; Axelrod, T.

$\mathrm{DOE} / \mathrm{DP}$

UCRI $-1 \mathrm{D}--123626$
$\mathrm{~T}-7405-\mathrm{ENG}-48$

SFENG48

03

$\mathrm{SF}$

012140-7502-9

CAIIFORNIA UNIVERSITY OF

UCRIIDI23626

M96009736

T/03/96

10

EN

UNL

P

EDB;ERA;EID;NTS

TIC

US

000

9513035
OS; NT 